\title{
Association of neuronal injury blood marker neurofilament light chain with mild-to-moderate COVID-19
}

\author{
Markus Ameres $^{1} \cdot$ Susanne Brandstetter ${ }^{2} \cdot$ Antoaneta A. Toncheva $^{1} \cdot$ Michael Kabesch $^{1} \cdot$ David Leppert $^{3}$. \\ Jens Kuhle ${ }^{3} \cdot$ Sven Wellmann ${ }^{1}$ (1)
}

Received: 4 June 2020 / Revised: 1 July 2020 / Accepted: 2 July 2020 / Published online: 9 July 2020

(C) The Author(s) 2020

Dear Sir,

Even though the coronavirus disease 2019 (COVID-19) affects primarily the respiratory system some reports describe nervous system involvement as well [1-3]. Headache and anosmia have been frequently described as neurological symptoms of mild-to-moderate COVID-19 but a direct impact of COVID-19 on neuronal integrity has not been clarified yet [4]. Therefore, a neuronal biomarker would be extremely useful to elucidate neuro-axonal injury during an infection with Severe Acute Respiratory Syndrome Coronavirus-2 (SARS-CoV-2) and in the post-infection follow-up period. Serum neurofilament light chain (sNfL) has recently been considered as a specific biomarker to quantitate neuroaxonal damage in several disorders of the peripheral and central nervous system [5]. Hence, sNfL might also serve as a sensitive screening and follow-up marker for neuronal injury in COVID-19 patients.

We conducted a prospective cohort study in 100 healthcare workers ( 84 females, 16 males) following a COVID-19 outbreak in a major German children's and women's hospital [6]. The Ethics Committee of the University of Regensburg

Jens Kuhle and Sven Wellmann these authors contributed equally to this work.

Sven Wellmann

sven.wellmann@ukr.de

1 University Children's Hospital Regensburg (KUNO), Hospital St. Hedwig of the Order of St. John, University of Regensburg, Steinmetzstr. 1-3, 93049 Regensburg, Germany

2 Research and Development Campus Regensburg (WECARE) at the Hospital St. Hedwig of the Order of St. John, University of Regensburg, Regensburg, Germany

3 Neurologic Clinic and Policlinic, Departments of Medicine, Biomedicine and Clinical Research, University Hospital Basel, University of Basel, Basel, Switzerland approved the study (file-number: 20-1767-101), and written informed consent was obtained from all study participants. They were categorized according to their SARS-CoV-2 infection status, $n=28$ tested positive, $n=72$ negative in PCR-based viral RNA amplification from nasopharyngeal swabs (Xpert@ Xpress SARS-CoV-2, Cepheid) [5]. To preserve anonymity of study participants, age was assessed in three categories (18-35 years $n=33,36-50$ years $n=37$ and 51-65 years $n=30$ ) [7]. sNfL concentrations were measured using the single molecule array (Simoa) NF-light ${ }^{\circledR}$ kit on the HD-X Analyzer (Quanterix, Lexington, MA) [5]. First, descriptive statistics were calculated. Then, a multivariable linear regression model was fitted with sNfL as dependent variable and with sex, age and COVID-19 status as independent variables.

All COVID-19 patients had mild-to-moderate symptoms and recovered after 1-3 weeks and showed no or only minor neurological symptoms, including anosmia and headache. First, sNfL measurement was done in COVID-19 patients 23 days (median, IQR 21-26) after onset of disease. sNfL levels for COVID-19 patients and for controls, stratified for age group, are depicted in Fig. 1. Median and interquartile range for COVID-19 patients were $4.5 \mathrm{pg} / \mathrm{ml}$ [IQR 3.7-5.7] for the age group 18-35 years, 9.6 [6.5-11.3] for the age group 36-50 years, and 11.6 [8.4-18.3] for the age group 51-65 years, respectively. sNFL levels for controls were 4.4 [3.5-5.5] for the youngest group, 6.8 [5.6-8.8] for the group 36-50 years, and 9.6 [8.2-11.2] for the oldest group (Table 1).

Since sNFL levels are highly dependent on age [8] the association between COVID-19 status and SNFL was determined using a multivariable linear regression model with COVID-19 status, age and sex as independent variables. This analysis revealed that COVID-19 status was significantly associated with sNfL $(b=1.87 ; p=0.005)$ when controlling for age and sex (Table 2). In COVID-19 patients with two sNfL measurements $(n=16$, time span between 


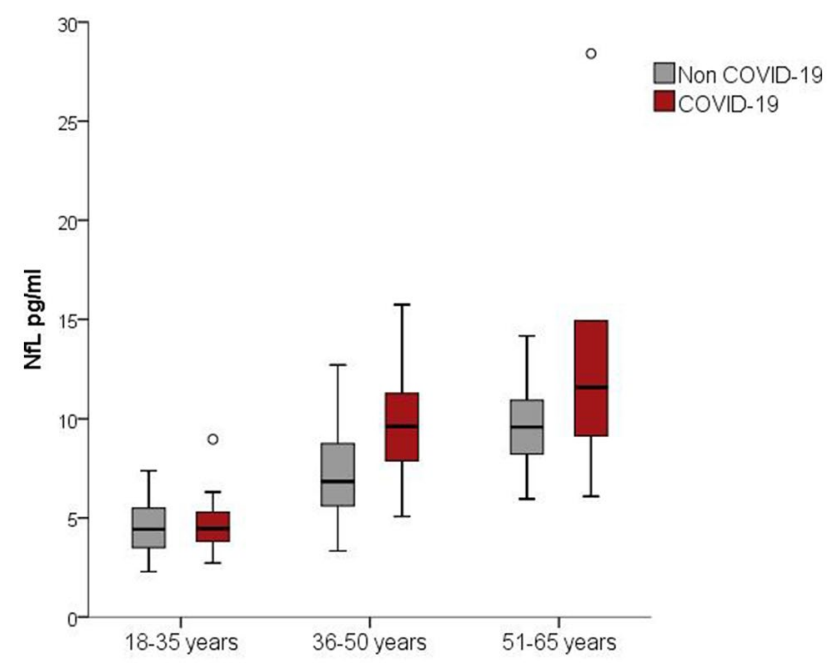

Fig. 1 Boxplots of sNfL concentrations in COVID-19 and control cases stratified by age group. Of note, COVID-19 status $(p=0.005)$ and age group $(p<0.001)$ are significantly associated with sNfL values in a multivariable linear regression analysis of sex, age and COVID-19 status

Table 1 Baseline characteristics of study participants stratified by COVID-19 status

\begin{tabular}{llc}
\hline & $\begin{array}{l}\text { Non COVID- } \\
19(n=72)\end{array}$ & COVID-19 $(n=28)$ \\
\hline Female $(N, \%)$ & $59(81.9)$ & $25(89.3)$ \\
Male $(N, \%)$ & $13(18.1)$ & $3(10.7)$ \\
Age group 18-35 years $(N, \%)$ & $20(27.7)$ & $13(46.4)$ \\
Age group 36-50 years $(N, \%)$ & $28(38.9)$ & $9(32.14)$ \\
Age group 51-65 years $(N, \%)$ & $24(33.3)$ & $6(21.4)$ \\
Respiratory symptoms $(N, \%)$ & & $17(60.7)$ \\
Neurological symptoms $(N, \%)$ & & $21(75.0)$ \\
\hline
\end{tabular}

Notes: respiratory symptoms included cough and shortness of breath; neurological symptoms included headache and anosmia

Table 2 Multivariable linear regression analysis of sex, age and COVID-19 status on sNfL

\begin{tabular}{llclr}
\hline & $b$ & SE B & $\beta$ & \multicolumn{1}{l}{$p$} \\
\hline Sex (female) & -0.02 & 0.84 & -0.00 & 0.981 \\
Age group 18-35 years & \multicolumn{2}{l}{ Reference category } & & \\
Age group 36-50 years & 3.38 & 0.72 & 0.44 & $<0.001$ \\
Age group 51-65 years & 6.10 & 0.74 & 0.76 & $<0.001$ \\
COVID-19 & 1.87 & 0.65 & 0.23 & 0.005 \\
\hline
\end{tabular}

Notes: $n=100$. Nagelkerke's $R^{2}=0.45 ; b$ regression coefficient, $S E B$ standard error (regression coefficient), $\beta$ standardized regression coefficient, $p$ significance value

the measurements was median 35 days, range 29-36 days), sNfL levels were highly correlated $(r=0.96)$.
$\mathrm{NfL}$ is a highly specific structural protein of neurons and elevated levels of sNfL are recognized as measures of acute or chronic neuro-axonal damage [5]. Our results from a study in health care workers without known comorbidities indicate that mild-to-moderate COVID-19 is associated with increased sNfL levels. Neurologic symptoms and complications in patients with SARS-CoV-2 infection have been reported by the first available studies during SARS-CoV-2 pandemic [1, 2]. However, these studies are restricted to hospitalized patients and, therefore, represent a population more likely to have severe neurological manifestations for a variety of reasons. Our results indicate for the first time that COVID-19 may affect the neuro-axonal integrity also in adults with a mild-tomoderate course of the disease. This new evidence for a more general neuro-destructive capability of SARS-CoV-2 also in mild-to-moderate COVID-19 patients should raise awareness for potential long-term neurologic sequelae following COVID-19. Of note, our study includes only a limited number of patients. In addition, information on participants' age was collected using very broad categories and we cannot exclude that there were age differences between COVID-19 patients and controls not accounted for in the statistical adjustment using age groups. To draw further conclusions, additional studies on SNfL and COVID-19 are needed.

Acknowledgements Open Access funding provided by Projekt DEAL.

Author contributions All authors contributed to the study conception and design. Material preparation, data collection and analysis were performed by MA, SB, AAT, DL and JK. The first draft of the manuscript was written by MA and all authors commented on previous versions of the manuscript. All authors read and approved the final manuscript.

Funding Funded by the Swiss National Research Foundation (320030_189140/1).

Data availability On request.

\section{Compliance with ethical standards}

Conflicts of interest Nothing to disclose.

Ethical approval The Ethics Committee of the University of Regensburg approved the study (file-number: 20-1767-101).

Open Access This article is licensed under a Creative Commons Attribution 4.0 International License, which permits use, sharing, adaptation, distribution and reproduction in any medium or format, as long as you give appropriate credit to the original author(s) and the source, provide a link to the Creative Commons licence, and indicate if changes were made. The images or other third party material in this article are included in the article's Creative Commons licence, unless indicated otherwise in a credit line to the material. If material is not included in the article's Creative Commons licence and your intended use is not 
permitted by statutory regulation or exceeds the permitted use, you will need to obtain permission directly from the copyright holder. To view a copy of this licence, visit http://creativecommons.org/licenses/by/4.0/.

\section{References}

1. Mao L et al (2020) Neurologic manifestations of hospitalized patients with coronavirus disease 2019 in Wuhan. China JAMA Neurol 10:e201127. https://doi.org/10.1001/jamaneurol .2020 .1127

2. Helms J et al (2020) Neurologic Features in Severe SARS-CoV-2 Infection. NEJM. https://doi.org/10.1056/NEJMc2008597

3. Romero-Sanchez CM et al (2020) Neurologic manifestations in hospitalized patients with COVID-19: the ALBACOVID registry. Neurology. https://doi.org/10.1212/WNL.0000000000009937

4. Lapostolle F et al (2020) Clinical features of 1487 COVID-19 patients with outpatient management in the greater Paris: the
COVID-call study. Intern Emerg Med. https://doi.org/10.1007/ s11739-020-02379-z

5. Khalil $\mathrm{M}$ et al (2018) Neurofilaments as biomarkers in neurological disorders. Nat Rev Neurol 14:577-589

6. Kabesch M, Roth S, Brandstetter S, Häusler S, Juraschko E, Weigl M, Wellmann S, Lang T, Schmidt B, Salzberger B, Ambrosch A (2020) Successful containment of COVID-19 outbreak in a large maternity and perinatal center while continuing clinical service. Pediatr Allergy Immunol. https://doi.org/10.1111/pai.13265

7. Brandstetter $S$, Roth $S$, Harner $S$, Buntrock-Döpke $H$, Toncheva A, Borchers N, Gruber R, Ambrosch A, Kabesch M (2020) Symptoms and immunoglobulin development in hospital staff exposed to a SARS-CoV-2 outbreak. Pediatr Allergy Immunol. https://doi. org/10.1111/pai.13278

8. Khalil M, Pirpamer L, Hofer E et al (2020) Serum neurofilament light levels in normal aging and their association with morphologic brain changes. Nat Commun 11(1):812. https://doi. org/10.1038/s41467-020-14612-6 